\title{
Neovaginal diverticula: pathophysiology of colonic diverticulosis revisited
}

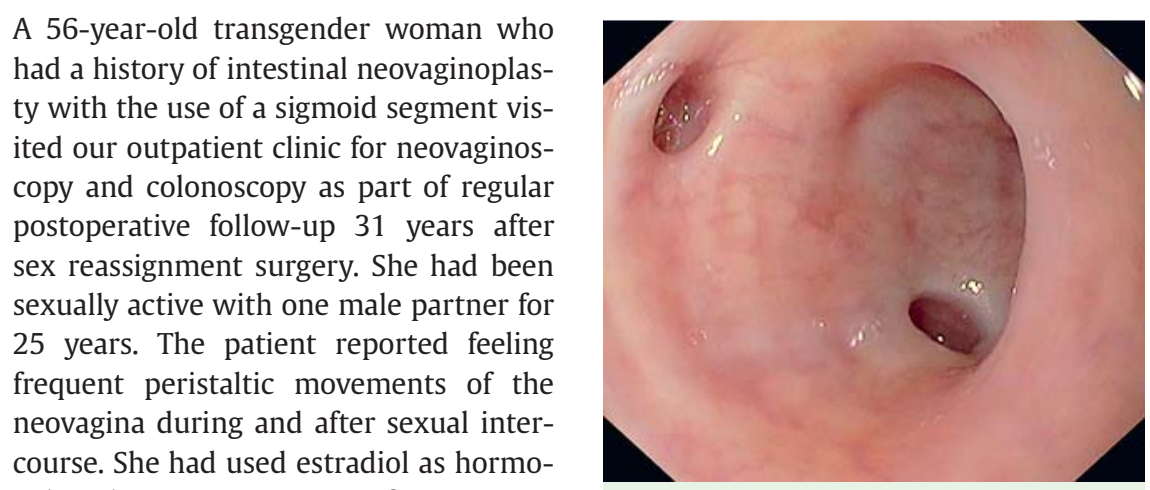
nal replacement treatment for 34 years, starting 3 years before sex reassignment surgery. Because of recurrent symptoms of neovaginal discharge and abdominal pain, multiple colonoscopic and neovaginoscopic procedures had been performed in the past, the last one 6 years before the current presentation. Only colonic diverticula had been observed.

At the outpatient visit, the woman again reported excessive neovaginal discharge. She dilated her neovagina weekly with a dilator. Endoscopic examination of the sigmoid-derived neovagina revealed a decreased vascular pattern with increased fragility of the mucosa, fitting an endoscopic diagnosis of diversion neovaginitis. Multiple neovaginal diverticula without concurrent inflammation were also observed ( $\bullet$ Fig. 1, Video 1). Endoscopic inspection of the rectosigmoid revealed the previously observed diverticulosis.

Colonic diverticula are observed at fragile sites of the muscular layer, such as where the vasa recta pass through the colonic wall. The precise pathophysiology of diverticulosis remains unclear. Fiber intake (either too much or too little) in the Western diet has been assumed to be one of the main factors in the development of colonic diverticulosis $[1,2]$. Increased intraluminal pressure also induces the formation of diverticula, especially at sites with the smallest radii, where the intraluminal pressure is highest (Laplace's law) [3]. Furthermore, structural alterations of the colonic muscular layer may lower its resistance to intraluminal pressure. For instance, collagen structure changes with age, making the colonic wall more rigid [4].
Fig. 1 Endoscopic examination reveals multiple diverticula without concurrent inflammation in the sigmoid-derived neovagina of a 56-year-old transgender woman.

This case report provides evidence that a diet high or low in fiber may not be a key factor in the development of diverticula. Increased intraluminal pressure, in our patient's case caused by frequent sexual intercourse and perhaps dilation, as well as by degenerative processes and structural changes in the colonic wall due to age, may well be a more important risk factor for the development of diverticulosis.

\section{Endoscopy_UCTN_Code_CCL_1AD_2AJ}

Competing interests: N. K. H. de Boer has served as a speaker for AbbVie and Merck Sharp \& Dohme. He has received an unrestricted research grant from Dr. Falk Pharma.

\section{Floor Bakker ${ }^{1}$, Wouter B. van der Sluis², Mark-Bram Bouman',3, Nanne K. H. de Boer ${ }^{1}$}

${ }^{1}$ Department of Gastroenterology and Hepatology, VU University Medical Centre, Amsterdam, the Netherlands

2 Department of Plastic, Reconstructive and Hand Surgery, VU University Medical Centre, Amsterdam, the Netherlands

${ }^{3}$ Centre of Expertise on Gender Dysphoria, VU University Medical Centre, Amsterdam, the Netherlands

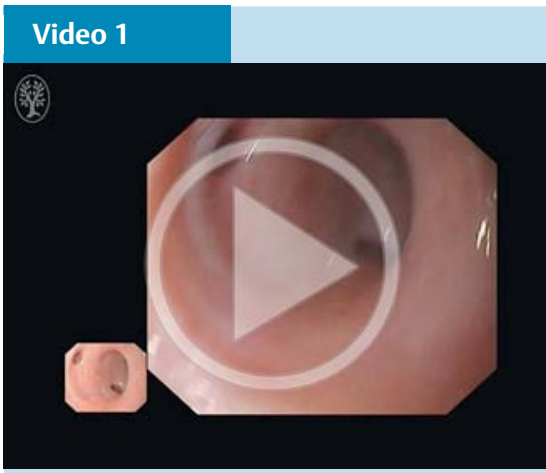

Endoscopic examination reveals multiple diverticula without concurrent inflammation in the sigmoid-derived neovagina of a 56-yearold transgender woman.

\section{References}

1 Tursi A, Papa A, Danese S. Review article: the pathophysiology and medical management of diverticulosis and diverticular disease of the colon. Aliment Pharmacol Ther 2015; 42: $664-684$

2 Peery AF, Barrett PR, Park D et al. A high-fiber diet does not protect against asymptomatic diverticulosis. Gastroenterology 2012; 142 : 266-272

3 Painter NS, Truelove SC, Ardran GM et al. Segmentation and the localization of intraluminal pressures in the human colon, with special reference to the pathogenesis of colonic diverticula. Gastroenterology 1965; 49: 169-177

4 Wess L, Eastwood MA, Wess TJ et al. Crosslinking of collagen is increased in colonic diverticulosis. Gut 1995; 37: 91 -94

Bibliography

DOI http://dx.doi.org/

10.1055/s-0035-1569661

Endoscopy 2015; 47: E611

(c) Georg Thieme Verlag KG

Stuttgart · New York

ISSN 0013-726X

Corresponding author

Floor Bakker, MD

Department of Gastroenterology and Hepatology VU University Medical Centre

P.O. Box 7057

$1007 \mathrm{MB}$

Amsterdam

The Netherlands

Fax: 31-20-4440554

f.bakker1@vumc.nl 